\title{
Gestão ambiental e ações associadas aos custos ambientais em indústrias madeireiras de Caçador, SC
}

\author{
Franciane L. Salamoni \\ Fundação Universidade Regional de Blumenau - FURB \\ E-mail: fransalamoni@gegnet.com.br
}

Alessandra V. Gallon

Fundação Universidade Regional de Blumenau - FURB

E-mail: alegallon@sodisa.com.br

Denise D.N. Machado

Fundação Universidade Regional de Blumenau - FURB

E-mail:delpra@furb.br

\section{RESUMO}

A crescente preocupação com a preservação ambiental requer a eliminação e/ou redução dos efeitos negativos do processo de produção industrial. Diante disso, o presente estudo busca verificar a gestão ambiental, através da percepção e adoção dos princípios dos indicadores ambientais, e identificar ações associadas aos custos ambientais executadas em indústrias madeireiras. Para tanto, foi realizado um estudo exploratório de multicasos, em indústrias madeireiras estabelecidas no município de Caçador/SC, com abordagem qualitativa dos dados. Como resultado da pesquisa, verificou-se que mesmo que a maioria das indústrias madeireiras do município de Caçador se preocupe em desempenhar uma boa gestão ambiental, já que apresentam relativa adoção dos princípios dos indicadores ambientais, estas ainda têm um longo caminho a trilhar na busca pela harmonia com o meio ambiente. Com relação a identificação dos custos ambientais, constatou-se que as ações executadas pelas madeireiras são essencialmente de custos de detecção e prevenção ambiental e que suas ações pró-ativa à gestão de custos ambientais são promitentes em termos de prevenção de danos ambientais e, conseqüentemente, em redução de custos.

Palavras-chave: Gestão ambiental. Indústrias madeireiras. Custos ambientais.

\section{Ambient management and action associates to the ambient costs in lumber industries of Caçador, SC, Brazil}

\section{ABSTRACT}

The increasing concern with the ambient preservation requires the elimination and/or reduction of the negative effect of the process of industrial production. In front of this, the present study it searches to verify the ambient management, through the perception and adoption of the principles of the ambient pointers, and to identify to action associates to the executed ambient costs in lumber industries. For in such a way, an exploratory study of 
multiple cases was carried through, in established lumber industries in the city of Caçador/SC, with qualitative boarding of the data. As result of the research, it was verified that exactly that the majority of the lumber industries of the city of Caçador if worries in to play a good ambient management, since these present relative adoption of the principles of the ambient pointers, still have a long way to tread in the search for the harmony with the environment. With regard to identification of the ambient costs, it was evidenced that the actions executed for the lumber are essentially of costs of detention and ambient prevention and that its pro-active action to the management of ambient costs is promissory in terms of prevention of ambient damages and, consequently, in reduction of costs.

Palavras-chave: Ambient management. Lumber industries. Ambient costs.

\section{INTRODUÇÃO}

Machado e Giombelli (2000) ressaltam que as indústrias estão buscando maior competitividade do mercado e, diante das exigências decorrentes da exportação e das legislações ambientais vigentes, obrigam-se a adotar programas de preservação ambiental.

As mudanças nas organizações ocorrem na implementação de ações voltadas aos seus empregados, processos, escolha da matéria-prima, seleção de fornecedores e atuação em seu ambiente por meio da participação em programas junto a comunidade onde a empresa está inserida.

Destacam, segundo (Gonçalves e Heliodoro, 2005) que "a responsabilidade social das empresas não pode ser ignorada pelas empresas que pretendem vencer nos mercados e economias modernas, sendo considerada atualmente como parte integrante da estratégia empresarial."

Dessa forma, (Souza, 2002) afirma que a gestão ambiental nas empresas "é atualmente condicionada pela pressão das regulamentações, pela bisca de melhor reputação, pela pressão de acionistas, investidores e bancos para que as empresas reduzam o risco ambiental, pela pressão de consumidores e pela própria concorrência. "

A conscientização sobre os problemas que afetam o meio ambiente nesta perspectiva, age como fator preponderante para compatibilização da expansão dos meios de produção de acordo com condições ambientais ideais. 
Nesse sentido, a responsabilidade social da empresa deve voltar-se para a eliminação e/ou redução dos efeitos negativos do processo de produção e preservação dos recursos naturais, principalmente os não renováveis, através da adoção de tecnologias eficientes, concomitantemente ao atendimento dos aspectos econômicos (Ribeiro, 1992).

De acordo com o Sindicato das Indústrias Madeireiras de Caçador (SIMCA, 2005), as madeireiras de Caçador se destacam pela alta tecnologia aplicada e pela busca constante de investimentos no âmbito florestal, foco principal para a sobrevivência das mesmas.

Diante do exposto surgem algumas indagações incentivadoras da pesquisa: Como se configura a gestão ambiental em madeireiras do município de Caçador/SC? Quais as ações executadas pelas madeireiras de Caçador referente as classificações dos custos ambientais?

Visando responder a essas questões, o objetivo da pesquisa é verificar a gestão ambiental, através da percepção e adoção dos princípios dos indicadores ambientais, e identificar ações associadas aos custos ambientais executadas em indústrias madeireiras. A relevância da pesquisa evidencia-se na medida em que se verifica uma crescente preocupação com a preservação ambiental no mundo, principalmente no que se refere ao descontrole dos desmatamentos e à poluição do meio ambiente. Também observa-se esforços de organizações para minimizar os efeitos da devastação de recursos, sejam eles recuperáveis ou não.

Quanto à organização do estudo, ele inicia com uma breve abordagem sobre o setor madeireiro catarinense e a importância do município de Caçador no setor, seguida de um apanhado teórico sobre o contexto empresarial e a gestão ambiental, e trata da gestão de custos ambientais e sua classificação. Na seqüência, evidencia o método e os procedimentos de pesquisa adotados. Em seguida faz a descrição e análise dos dados coletados e apresenta as conclusões da pesquisa. 
Gestão ambiental e ações associadas aos custos ambientais em indústrias madeireiras de

Caçador, SC

Franciane L. Salamoni, Alessandra V. Gallon, Denise D.N. Machado

\section{O SETOR MADEIREIRO CATARINENSE E A IMPORTÂNCIA DO MUNICÍPIO DE CAÇADOR NO SETOR}

Dentre os diversos agronegócios do Estado de Santa Catarina, o setor madeireiro corresponde a 6,5\% da participação na indústria catarinense levando em consideração o valor da transformação industrial (Federação das Indústrias do Estado de Santa Catarina - FIESC, 2006).

A Tabela 1 apresenta a produção dos principais produtos de extração vegetal (madeiras) em 2001 e 2002 em Santa Catarina e no Brasil, respectivamente.

Tabela 1. Produção dos principais produtos da extração vegetal em 2001 e 2002 (madeiras)

\begin{tabular}{|c|c|c|c|c|c|c|}
\hline \multirow[t]{2}{*}{ Produto } & \multicolumn{3}{|c|}{2001} & \multicolumn{3}{|c|}{2002} \\
\hline & SC & BR & $\%$ SC/BR & SC & BR & $\%$ SC/BR \\
\hline Carvão vegetal & & & & & & \\
\hline Quantidade (t) & 12.197 & 1.729 .319 & 0,71 & 9.050 & 1.955 .377 & 0,46 \\
\hline $\begin{array}{l}\text { Valor ( } \mathrm{R} \$ \text { mil) } \\
\text { Lenha }\end{array}$ & 2.653 & 226.646 & 1.17 & 2.282 & 441.571 & 0,52 \\
\hline Quantidade $\left(\mathrm{m}^{3}\right)$ & 2.100 .240 & 49.001 .583 & 4,29 & 2.022 .836 & 49.502 .542 & 4,09 \\
\hline Valor ( $\mathrm{R} \$$ mil) & 19.752 & 324.008 & 6,10 & 22.719 & 447.172 & 5,08 \\
\hline Madeira em Tora & & & & & & \\
\hline Quantidade $\left(\mathrm{m}^{3}\right)$ & 98.813 & 20.069 .287 & 0,49 & 92.821 & 21.374 .527 & 0,43 \\
\hline Valor ( $\mathrm{R} \$ \mathrm{mil})$ & 3.941 & 995.282 & 0,40 & 4.227 & 1.338 .786 & 0,30 \\
\hline
\end{tabular}

Fonte: IBGE (in FIESC, v. 14, 2004, p. 53).

Conforme o (SIMCA, 2005) o setor madeireiro é responsável por $62 \%$ do movimento econômico do município de Caçador e gera em torno de 6.000 empregos diretos. (Bazzanella, 2004) ressalta que "a preocupação em preservar o meio ambiente em Caçador é tarefa que faz parte do dia a dia das empresas".

\section{O CONTEXTO EMPRESARIAL E A GESTÃO AMBIENTAL}

Embora importantes movimentos de regulamentação de políticas ambientais já tenham ocorrido na década de 30 , somente por volta do final da década de 60 que aumentou a preocupação com o meio ambiente. É importante observar que o ambientalismo não possui uma data de nascimento determinada e tentar encontrar suas raízes, consiste principalmente da necessidade de se ter explicações para sua 
crescente importância (Duarte, 1997).

De acordo com (Tinoco e Kraemer, 2004), o mundo passou a ter uma nova consciência ambiental surgida no bojo das transformações sociais e culturais que ocorreram nas décadas de 60 e 70, ganhou dimensão e situou o meio ambiente como um dos princípios fundamentais do homem moderno.

A partir da década de 70, conforme (Gonçalves e Heliodoro, 2005), vem ocorrendo uma "evolução na atitude das empresas face ao ambiente, passando-se de uma situação de ausência de preparação, para estratégias que envolvem uma crescente integração dos aspectos ambientais e do conceito de sustentabilidade na cultura e gestão empresarial. "

O reconhecimento de que o meio ambiente necessitava de cuidados, fez com que as empresas de grande porte começassem, nos anos 80 , a analisar os investimentos ambientais como uma vantagem competitiva perante os consumidores, e não como custo. Segundo (Andrade et. al., 2002), os gastos com proteção ambiental começam a ser vistos pelas empresas líderes, não primordialmente como custos, mas como investimentos no futuro e, paradoxalmente, como vantagem competitiva.

Com a criação das políticas ambientais, a sociedade começa a mudar seu comportamento, e desta forma se difunde o que se chama de "cultura ambiental". Estas políticas propiciaram a difusão do que se denominou "a cultura dos Rs", referindo-se à consoante inicial de várias palavras usadas na gestão ambiental, quais sejam: reduzir, reusar, reciclar, recusar, refil, repetir, reparar, remediar, reivindicar, retornar, entre outras (Ferreira, 2003).

A cultura ambiental para (Ferreira, 2003) é formada pela mudança de comportamento alcançada com informações e práticas ambientais que são implantadas na organização. Por meio delas, funcionários são educados sobre o meio ambiente, modificando seus comportamentos para se adequarem às novas práticas.

Já (Gobbi e Brito, 2005) destacam que os debates em torno da questão ambiental ganharam expressa legitimidade social, a ponto de se tornarem objeto de reflexão das organizações, que passaram a repensar suas práticas de produção e a formular políticas de gestão ambiental. 
Gestão ambiental e ações associadas aos custos ambientais em indústrias madeireiras de

Caçador, SC

Franciane L. Salamoni, Alessandra V. Gallon, Denise D.N. Machado

Segundo (Rosen, 2001), há fundamentalmente três razões para que as empresas busquem melhorar sua performance ambiental: o regime regulatório internacional, as mudanças do mercado, tanto de fatores, quanto de produtos e a transformação do conhecimento, com crescentes descobertas e publicidade sobre as causas e consequências dos danos ambientais.

As empresas segundo (Barbiere, 2004) sofrem pressões de vários setores para se adequar às regulamentações ambientais, como por exemplo: importadores de países com conscientização ambiental mais rigorosa exigem que a empresa vendedora adote políticas ambientais que estes considerem justas; e, investidores procuram cada vez mais minimizar os riscos de investimentos direcionando suas atividades para empresas que não apresentem passivos ambientais.

Entretanto, (Gonçalves e Heliodoro, 2005) afirmam que o reconhecimento da responsabilidade social no que diz respeito a proteção ambiental não tem sido tarefa fácil e a resistência por parte das empresas se dá principalmente pelos altos custos para aquisição de novas tecnologias para a redução e eliminação dos resíduos tóxicos e pela inexistência de legislação apropriada ao nível ambiental.

Ressalta-se que apesar das dificuldades de implantação de uma gestão ambiental adequada por parte das empresas, os investimentos econômicos em inovações relacionadas ao meio ambiente podem se tornar fontes significativas de vantagem competitiva. A variável ambiente para (Wernke, 2001) pode ser utilizada como uma ferramenta que permite a empresa destacar-se das outras empresas, suas concorrentes, e ganhar participação de mercado, através, por exemplo, do uso de materiais recicláveis e de financiamento de programas de preservação ambiental.

Já (Robles Júnior, 2003) destaca que "a solução dos problemas ambientais é consequência da existência de um sistema de gestão ambiental bem administrado, para identificação clara dos problemas e suas causas." Nesta perspectiva, torna-se fundamental que a empresa desfrute de uma adequada gestão de custos ambientais. 
Gestão ambiental e ações associadas aos custos ambientais em indústrias madeireiras de

Caçador, SC

Franciane L. Salamoni, Alessandra V. Gallon, Denise D.N. Machado

\section{GESTÃO DE CUSTOS AMBIENTAIS}

Em consequência da importância da preservação do meio ambiente, as empresas se defrontam com um novo e crescente tipo de custo, os denominados 'custos ambientais' (Cammarano, 2004).

Sobre o termo custo ambiental, (Campos, 1996) salienta que este é um termo de difícil conceituação, não apresentando definição clara e objetiva, e que a maior dificuldade ao se trabalhar com custos ambientais, é o fato de estes serem, em sua maioria, custos intangíveis.

Entretanto (Robles Júnior, 2003) define custos intangíveis como "aqueles com alto grau de dificuldade para serem quantificados, embora se perceba claramente a sua existência. Normalmente não podem ser diretamente associados ao produto ou processo."

Para (Tinoco e Kraemer, 2004), os custos intangíveis ou também chamados custos contingentes "são, de maneira geral, potenciais custos internos futuros, que podem impactar nas operações efetivas da empresa. "

No que diz respeito aos gastos ambientais, (Ribeiro e Rocha, 1999) relatam que "são todos aqueles relacionados direta ou indiretamente, ao processo de gerenciamento ambiental, processo este que compreende todas as atividades inerentes ao controle, preservação e proteção ao meio ecológico, além de recuperação de áreas contaminadas".

Segundo (Hansen e Mowen, 2001), sob o ponto de vista empresarial, os custos ambientais, também conhecidos como custos de qualidade ambiental, "são custos incorridos porque existe uma má qualidade ambiental ou porque pode existir uma má qualidade ambiental. "

Em função das mudanças na relação entre empresas e o meio ambiente, observa-se a importância da identificação dos custos ambientais pelas empresas para a consecução de informações consistentes relativas ao quanto se vem perdendo ou deixando de ganhar com processos e atividades que degradam o meio ambiente.

De acordo com a Federação e Centro das Indústrias do Estado de São Paulo 
(FIESP, 2004), a melhoria na relação da empresa com o meio ambiente é capaz de otimizar a produtividade dos recursos utilizados, implicando em benefícios diretos para a empresa, o processo industrial e o produto, como mostra o Quadro 1.

\begin{tabular}{|c|c|c|}
\hline Benefícios para a empresa & Benefícios para o processo produtivo & Benefícios para o produto \\
\hline $\begin{array}{l}\text { - } \quad \begin{array}{c}\text { melhoria da imagem da } \\
\text { empresa; }\end{array} \\
\text { - } \quad \text { manutenção dos atuais e } \\
\text { conquista de novos nichos de } \\
\text { mercado; } \\
\text { - } \quad \text { redução do risco de } \\
\text { desastres ambientais; } \\
\text { - } \quad \text { adição do valor com a } \\
\text { eliminação ou minimização dos } \\
\text { resíduos; } \\
\text { - menor incidência de custos } \\
\text { com multas e processos judiciais; } \\
\text { e } \\
\text { - } \quad \text { maior diálogo com os órgãos } \\
\text { de controle e fiscalização. }\end{array}$ & 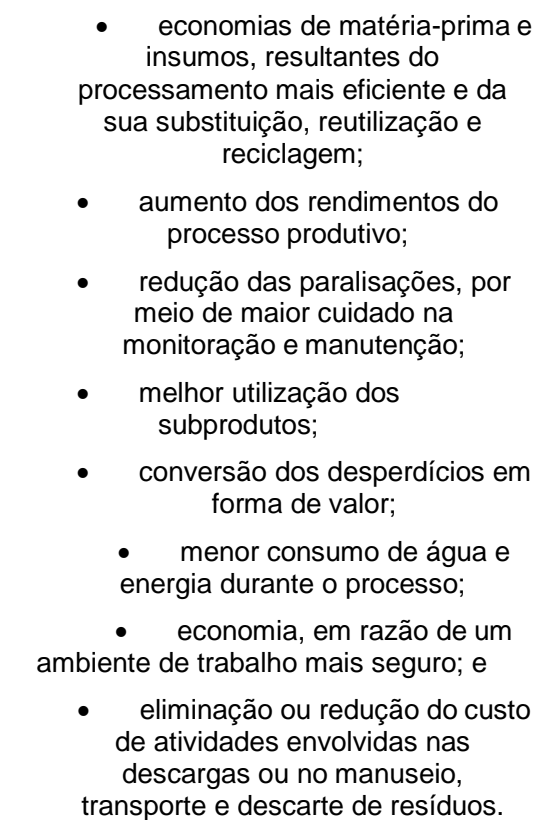 & $\begin{array}{l}\text { - } \quad \text { mais qualidade e } \\
\text { uniformidade; } \\
\text { - } \quad \text { redução dos custos (por } \\
\text { exemplo, com a substituição de } \\
\text { materiais); } \\
\text { - } \quad \text { redução nos custos de } \\
\text { embalagens; } \\
\text { - } \quad \text { utilização mais eficiente } \\
\text { dos recursos; } \\
\text { - } \quad \text { aumento da segurança; } \\
\text { redução do custo líquido do } \\
\text { descarte pelo cliente; e } \\
\text { - maior valor de revenda e } \\
\text { de sucata do produto. }\end{array}$ \\
\hline
\end{tabular}

Quadro 1. Benefícios causados pela melhoria na relação entre a empresa e o meio ambiente Fonte: Cartilha de indicadores de desempenho ambiental na indústria - FIESP (2004).

Percebe-se que a melhoria na relação entre a empresa e o meio ambiente traz diversos benefícios para ambos com a gestão do desperdício, o controle da poluição, gestão da água e da energia, obediência às leis, entre outros.

O mesmo ocorre com relação à adequada gestão dos custos ambientais pela empresa. As informações dos custos ambientais relacionados aos processos serviriam como indicativo no sentido de propor melhorias para diminuir ou até mesmo eliminar tais custos, gerando vantagem para a empresa. Quanto ao meio ambiente, com a identificação dos custos ambientais, poder-se-ia propor melhorias nos processos que resultem na diminuição do dano causado ao meio ambiente, beneficiando o meio ambiente (Campos, 1996).

$\mathrm{Na}$ sequência, para que a gestão de custos ambientais possa ser melhor 
Gestão ambiental e ações associadas aos custos ambientais em indústrias madeireiras de Caçador, SC

Franciane L. Salamoni, Alessandra V. Gallon, Denise D.N. Machado

compreendida apresenta-se a classificação dos custos ambientais.

\section{CLASSIFICAÇÃO DOS CUSTOS AMBIENTAIS}

Para (Moura, 2000, in Robles Júnior, 2003), "os custos da qualidade ambiental podem ser considerados de dois tipos: custos de controle e os custos resultantes da falta de controle sobre os processos industriais e gerenciais."

A Figura 1 demonstra a identificação dos custos ambientais de acordo com a classificação do autor.

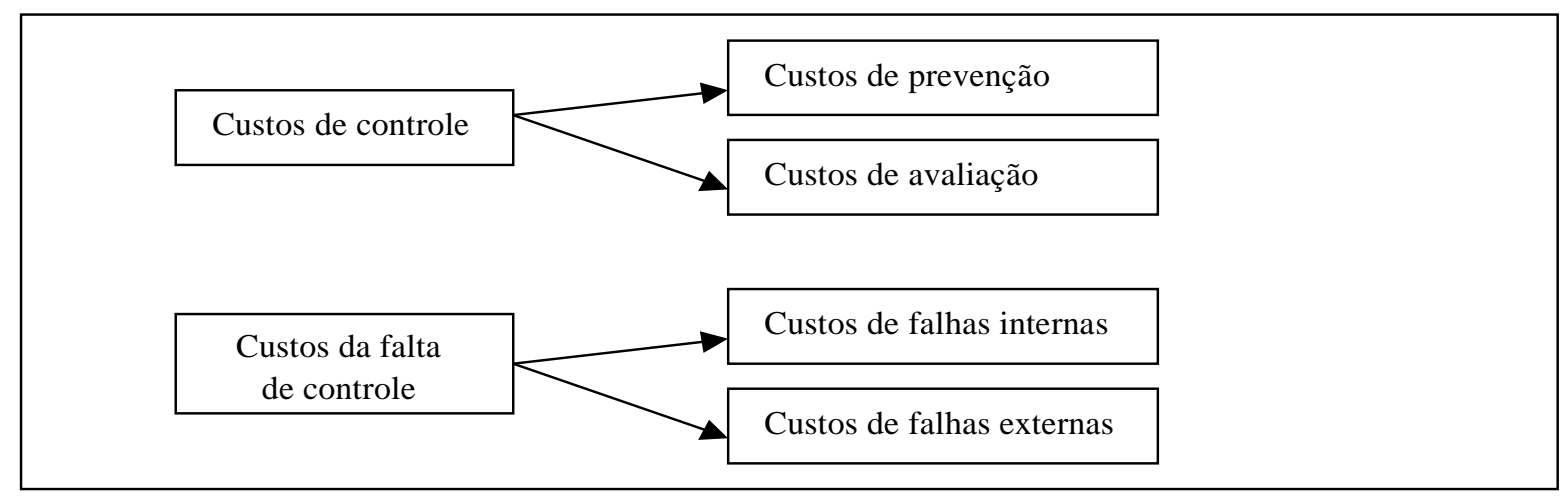

Figura 1. Identificação dos custos ambientais.

Fonte: Robles Júnior (2003, p. 140)

Os custos ambientais, dessa forma, estão associados com a criação, detecção, correção e prevenção da degradação ambiental. Os custos de controle podem ser classificados em custos de prevenção e custos de avaliação ou de detecção; e os custos da falta de controle, classificados em custos de falhas internas e de falhas externas.

Já (Graedel e Allenby, 1996) conceituam os custos de prevenção ambiental como "o uso de materiais, processos, ou práticas que reduzam ou eliminem a quantidade ou toxidade de resíduos na fonte de geração através de atividades que promovam, encorajam ou exijam modificações nos padrões comportamentais básicos da empresa". Nesta perspectiva, os autores expõem a prevenção como algo muito mais viável para a indústria do que o controle e a correção. 
Com relação à viabilidade da ênfase nos custos ambientais de prevenção em detrimento dos custos ambientais da falta de controle, (Hansen e Mowen, 2001) relatam que "uma abordagem pró-ativa é mais promissora em termos de prevenção de danos ambientais e, simultaneamente, em redução de custos". Complementam mencionando que "reguladores e empresas estão começando a perceber que pode ser menos oneroso prevenir a poluição do que remediá-la".

São exemplos de atividades de prevenção ambiental, segundo (Hansen e Mowen, 2001): avaliação e seleção de fornecedores, avaliação e seleção de equipamentos de controle da poluição, projeção de processos e produtos para reduzir ou eliminar os contaminadores, treinamento de empregados, estudo dos impactos ambientais, auditoria dos riscos ambientais, execução de pesquisas ambientais, desenvolvimento de sistemas de gestão ambiental, reciclagem de produtos e obtenção do certificado ISO 14001.

No que tange aos custos de avaliação ou detecção ambiental, (Robles Júnior, 2003) afirma que estes "são custos despendidos para manter os níveis de qualidade ambiental da empresa, por meio de trabalhos de laboratórios e avaliações formais do sistema de gestão ambiental ou sistema gerencial que se ocupem de garantir um bom desempenho ambiental da empresa". Estes custos são incorridos ao verificar se os processos e produtos da empresa estão cumprindo as normas ambientais apropriadas.

Entretanto (Hansen e Mowen, 2001) exemplificam as seguintes atividades como de avaliação e detecção ambiental: auditorias ambientais, inspeção de produtos e processos (para averiguar a conformidade ambiental), o desenvolvimento de medidas de desempenho ambiental, a execução de testes de contaminação, a verificação do desempenho ambiental de fornecedores e a medição de níveis de contaminação.

Com relação aos custos da falta de controle, estes podem ser de falhas ambientais internas (custos incorridos pelo não-atendimento de normas, padrões, procedimentos operacionais explícitos de gestão ambiental e correções de nãoconformidades) e de falhas ambientais externas (custos da qualidade ambiental insatisfatória e não-conformidades fora dos limites da empresa, resultantes de uma gestão ambiental inadequada) (Robles Júnior, 2003). 
Gestão ambiental e ações associadas aos custos ambientais em indústrias madeireiras de

Caçador, SC

Franciane L. Salamoni, Alessandra V. Gallon, Denise D.N. Machado

São exemplos de atividades de falhas internas segundo (Hansen e Mowen, 2001): operação de equipamento para minimizar ou eliminar poluição, tratamento e descarte de materiais tóxicos, manutenção de equipamento para poluição, licenciamento de instalações para a produção de contaminantes, retrabalhos em processos causados por não-conformidade ambientais e reciclagem de sucata.

De acordo com (Hansen e Mowen, 2001), os custos de falhas ambientais externas podem ser classificados em: custos realizados de falhas externas (custos incorridos e pagos pela empresa) e custos não-realizados de falhas externas (custos sociais causados pela empresa, mas incorridos e pagos por parte fora da empresa).

São exemplos de atividades realizadas de falhas externas segundo (Hansen e Mowen, 2001): limpeza de um rio ou lago poluído, limpeza de solo contaminado, uso ineficiente de materiais e energia, indenização por acidentes pessoais provenientes de más práticas ambientais, restauração da terra ao estado natural e perda de vendas causada por uma má reputação ambiental.

Os exemplos de custos sociais, segundo os autores, incluem: receber cuidados médicos por causa do ar poluído, perder empregos por causa de contaminação, perder um rio ou lago de uso recreativo por causa da contaminação e danificar ecossistemas devido ao descarte de resíduos sólidos.

Diante do exposto, pode-se observar que a utilização pelas empresas de medidas eficazes para a qualidade ambiental, identificando e buscando reduzir ou eliminar os custos ambientais (de controle, correção e falhas existentes) e priorizando os custos de prevenção ambiental, minimiza a ocorrência das falhas relacionadas ao processo produtivo e ao meio ambiente.

\section{MÉTODO E PROCEDIMENTOS DE PESQUISA}

O método empregado na presente pesquisa é de natureza exploratória, a qual foi realizada por meio de estudo multicasos, com abordagem qualitativa dos dados. Para (Cervo e Bervian, 1996), a pesquisa exploratória é responsável por observar, registrar, analisar e correlacionar os fatos ou fenômenos sem manipulá-los. O estudo multicasos 
Gestão ambiental e ações associadas aos custos ambientais em indústrias madeireiras de

Caçador, SC

Franciane L. Salamoni, Alessandra V. Gallon, Denise D.N. Machado

foi intensivo em 23 das 52 indústrias madeiras de médio porte estabelecidas no município de Caçador, cujas denominações sociais declina-se revelar para evitar constrangimentos aos respondentes.

Quanto aos procedimentos de coleta de dados, optou-se por adotar, inicialmente, entrevista semi-estruturada. Segundo (Triviños, 1987), a entrevista semi-estruturada é a que parte de certos questionamentos básicos, apoiados no referencial teórico e pressupostos, que provocam novos questionamentos no transcorrer da entrevista e influenciam a elaboração do conteúdo da pesquisa.

Após a entrevista, aplicou-se um questionário contendo questões fechadas. $\mathrm{O}$ questionário tem que ter clareza e limitado em extensão e estar acompanhado de notas que expliquem a natureza da pesquisa e ressaltam a importância e necessidade das respostas, a fim de motivar o informante (Colauto e Beuren, 2004).

Quanto aos procedimentos sistemáticos para a descrição e explicação dos fenômenos, o estudo desenvolveu-se num ambiente que preconizou a abordagem qualitativa. O método qualitativo, conforme (Richardson, 1999), caracteriza-se pelo não emprego de instrumental estatístico como base no processo de análise de um problema. Isto é, não se atém a numerar ou medir unidades ou categorias homogêneas.

Embora tenha sido adotado o rigor científico necessário em pesquisa dessa natureza, ressalta-se o fato do estudo se circunscrever em indústrias catarinenses estabelecidas em um único município. Esta estratégia de pesquisa se constitui em uma limitação, uma vez que seus resultados não podem ser generalizáveis a outros municípios catarinenses, dado as particularidades do sujeito da pesquisa.

\section{DESCRIÇÃO E ANÁLISE DOS RESULTADOS DA PESQUISA}

Nas entrevistas e questionários aplicados, os 23 respondentes foram questionados inicialmente sobre a percepção e adoção dos princípios dos indicadores ambientais, para a verificação de suas gestões ambientais. Na seqüência, indagou-se sobre suas ações executadas associadas aos custos ambientais. 
Gestão ambiental e ações associadas aos custos ambientais em indústrias madeireiras de

Caçador, SC

Franciane L. Salamoni, Alessandra V. Gallon, Denise D.N. Machado

\subsection{Percepção e adoção de indicadores ambientais}

Segundo (Diaz-Moreno, 1999), indicadores ambientais são variáveis ou estimativas ambientais que possuem informações de forma agregada e sintética sobre um fenômeno. Para (Possamai, 2002), indicadores ambientais são definidos como ferramentas que de modo claro e simples, e em uma primeira instância, permitiriam um melhor conhecimento das complexas relações entre o meio ambiente, os processos econômicos e a dinâmica social.

$\mathrm{Na}$ Figura 2 apresenta-se os resultados da percepção das indústrias madeireiras de Caçador sobre alguns princípios dos Indicadores Ambientais (IA) relacionados ao setor.

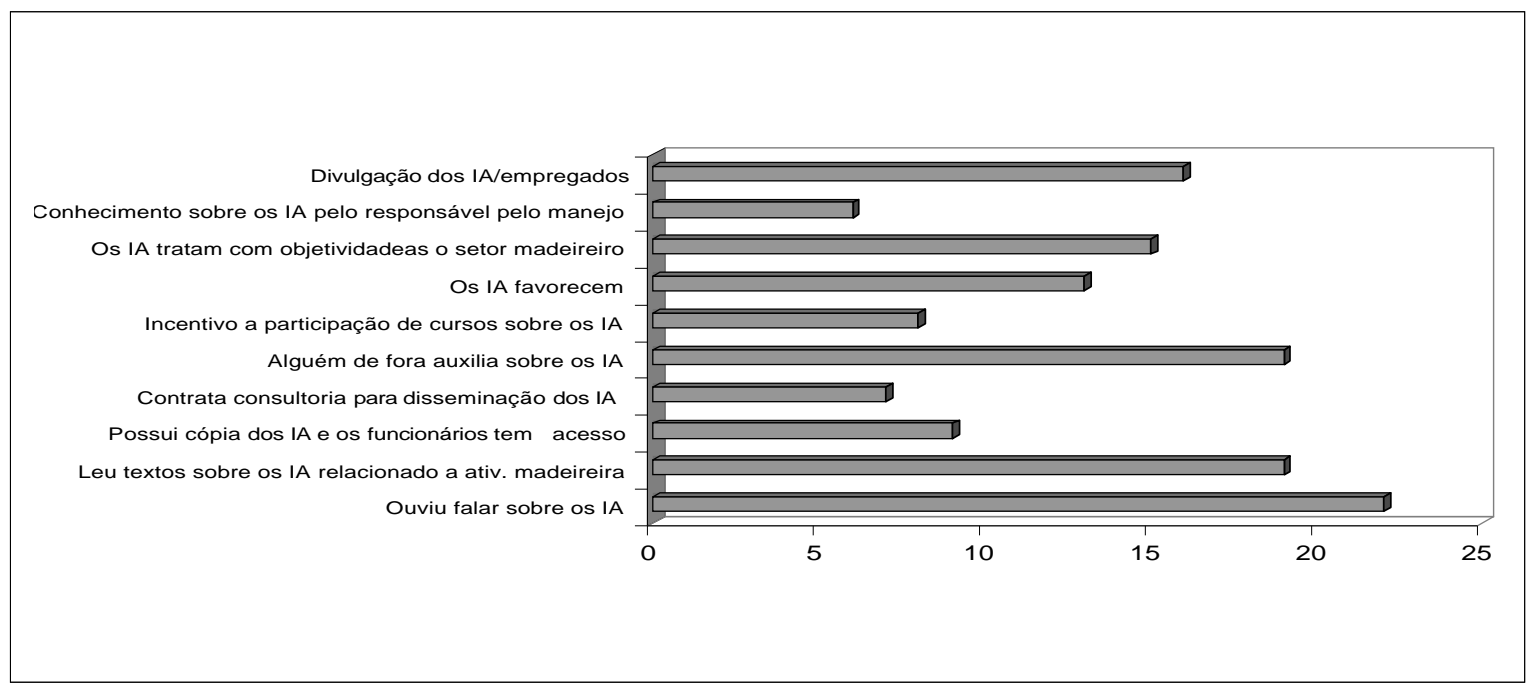

Figura 2. Percepção dos princípios dos indicadores ambientais Fonte: dados da pesquisa.

Com relação à percepção dos princípios dos indicadores ambientais questionados, observa-se que 22 empresas já ouviram falar sobre os indicadores ambientais e que em 19 empresas já leram textos que abordam sobre os indicadores ambientais relacionados a indústria. 
Gestão ambiental e ações associadas aos custos ambientais em indústrias madeireiras de

Franciane L. Salamoni, Alessandra V. Gallon, Denise D.N. Machado

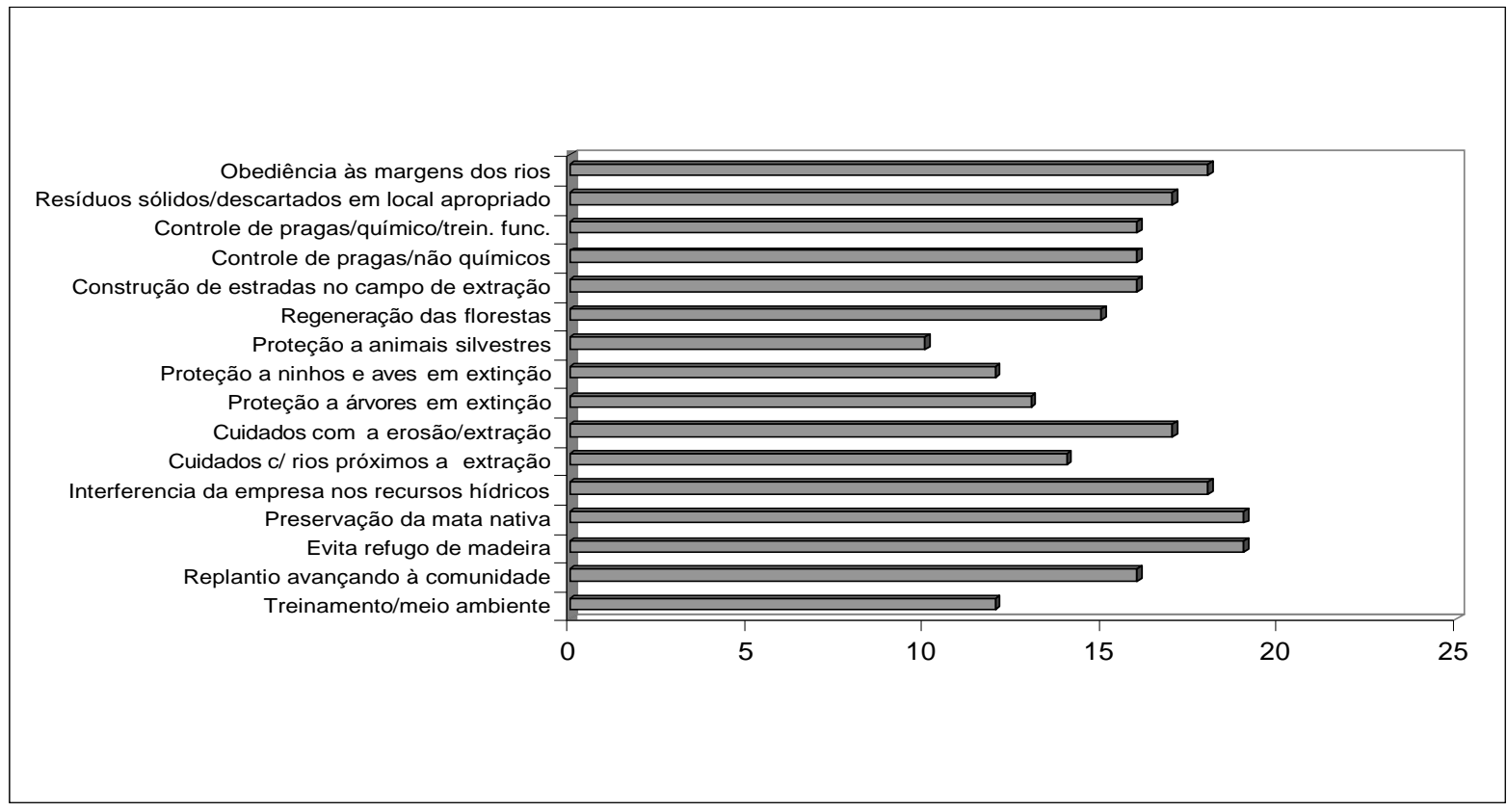

Figura 3. Adoção dos princípios dos indicadores ambientais

Fonte: dados da pesquisa.

No que tange à adoção dos princípios dos indicadores ambientais questionados, verifica-se que 19 empresas evitam deixar refugo de madeira tanto no campo de extração como no ambiente de transformação e buscam preservar a mata nativa. Em 18 empresas procura-se não interferir na qualidade e quantidade dos recursos hídricos e busca-se obedecer ao artigo $2^{\circ}$ do Código Florestal que discorre sobre as faixas marginais dos rios. Por outro lado, apenas 10 empresas se preocupam em proteger os animais silvestres. Das 23 empresas, somente 12 realizam treinamentos contínuos sobre meio ambiente e apenas 13 protegem árvores em extinção.

Foram apresentadas as principais razões para a adoção dos indicadores pelas empresas pesquisadas, entre elas destacam-se: conquista de mercados internacionais; preservação do meio ambiente sem comprometimento da produção; maiores vendas para o mercado nacional; proteção ao meio ambiente como garantia da convivência harmônica com a sociedade; preocupação com o status e o reconhecimento nacional e internacional; e, estar dentro das normas do setor.

Diante do exposto, percebe-se que mesmo que a maioria das indústrias madeireiras do município de Caçador se preocupe em desempenhar uma boa gestão 
Gestão ambiental e ações associadas aos custos ambientais em indústrias madeireiras de Caçador, SC

Franciane L. Salamoni, Alessandra V. Gallon, Denise D.N. Machado

ambiental, já que apresentam relativa adoção dos princípios dos indicadores ambientais, estas ainda têm um longo caminho a trilhar na busca pela harmonia com o meio ambiente. Tal fato vai de encontro a afirmado por Bazzanella (2004, p. 6), que afirma que "a preocupação em preservar o meio ambiente em Caçador é tarefa que faz parte do dia a dia das empresas".

\subsection{Ações executadas associadas aos custos ambientais}

Com o objetivo de identificar as ações executadas pela empresa associadas aos custos ambientais demonstra-se, a partir de exemplos, as atividades relacionadas que são executadas e que não são executadas pelas 23 indústrias madeireiras estabelecidas no município de Caçador/SC. As ações compreendem quatro categorias de custos: custos de prevenção ambiental, custos de detecção ou avaliação ambiental, custos de falhas ambientais internas e custos de falhas ambientais externas.

Para cada categoria de custos ambientais, com base na fundamentação teórica e na observação da realidade da empresa, foram listadas possíveis ações. Na Figura 4 demonstra- se os resultados relacionados aos custos de prevenção ambiental.

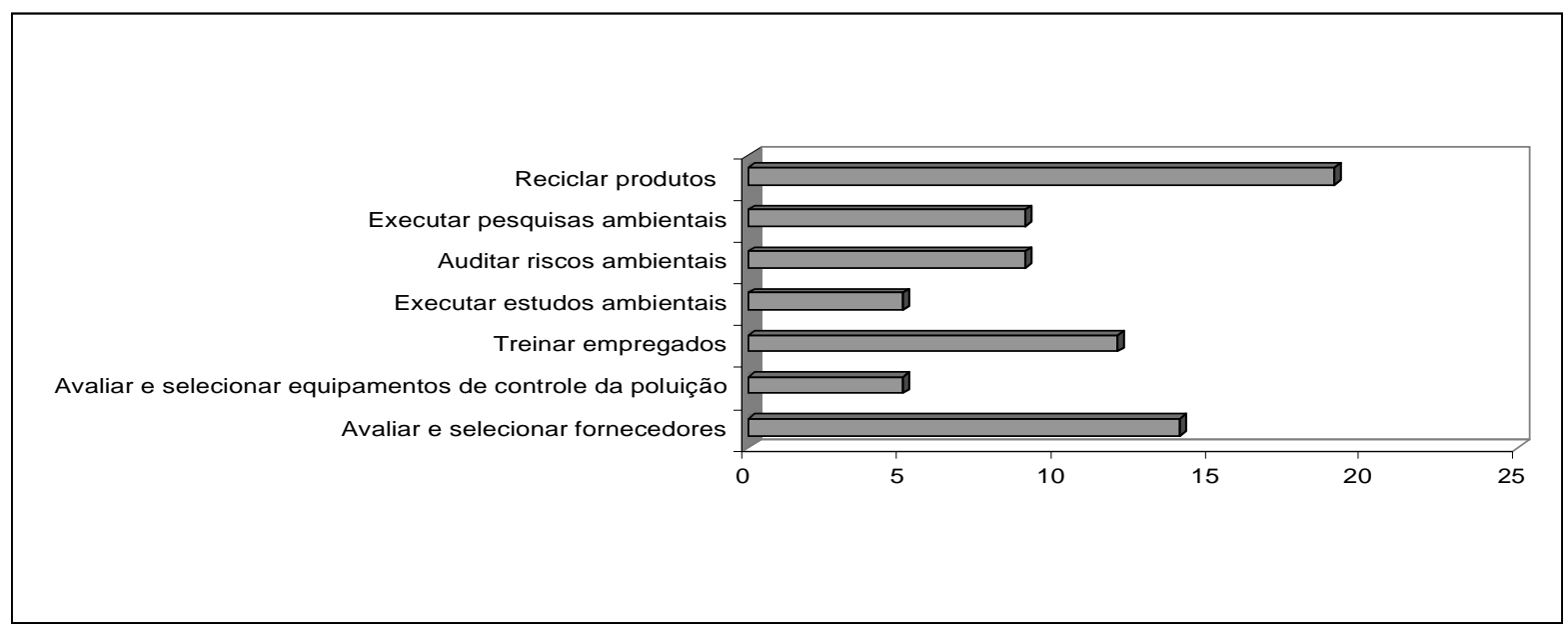

Figura 4. Atividades de prevenção ambiental Fonte: dados da pesquisa.

Verifica-se que as atividades de prevenção mais executadas relacionadas a 
custos ambientais pelas empresas são: a reciclagem de produtos, seguida da avaliação e seleção dos fornecedores e pelo treinamento dos empregados quanto ao meio ambiente. Entretanto, apenas 5 empresas avaliam e selecionam equipamentos de controle da poluição e executam pesquisas ambientais.

Além das atividades elencadas na Figura 4 outras atividades foram questionadas como projetar processos e produtos para reduzir ou eliminar contaminadores; desenvolver sistemas de gestão ambiental; e, obter certificado ISO 14001. Ressalta-se que estas atividades de prevenção ambiental não são executadas pelas respondentes.

$\mathrm{Na}$ Figura 5 apresenta-se os resultados relacionados aos custos de detecção ou avaliação ambiental.

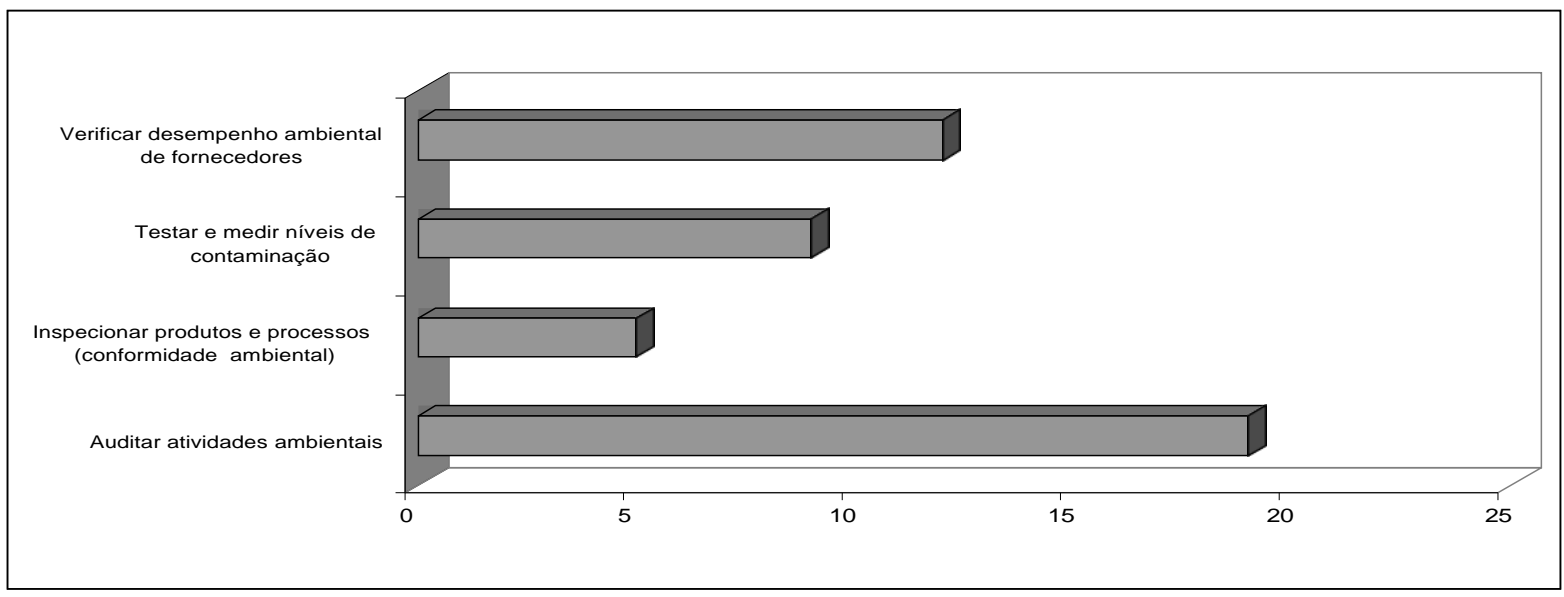

Figura 5. Atividades de detecção ambiental Fonte: dados da pesquisa.

Percebe-se que entre as atividades de detecção listadas, 19 empresas executam auditorias de atividades ambientais, 12 verificam o desempenho ambiental de seus fornecedores e 9 testam e/ou medem seus níveis de contaminação. Apenas 5 empresas inspecionam com frequência se seus processos e produtos seguem padrões ambientais ideais.

Além das atividades elencadas na Figura 5 outras atividades foram questionadas como desenvolver medidas de desempenho ambiental e efetuar testes de contaminação. Ressalta- se que estas atividades de detecção ambiental não são 
Gestão ambiental e ações associadas aos custos ambientais em indústrias madeireiras de Caçador, SC

Franciane L. Salamoni, Alessandra V. Gallon, Denise D.N. Machado

executadas pelas respondentes.

A Figura 6 demonstra-se os resultados relacionados aos custos de falhas ambientais internas.

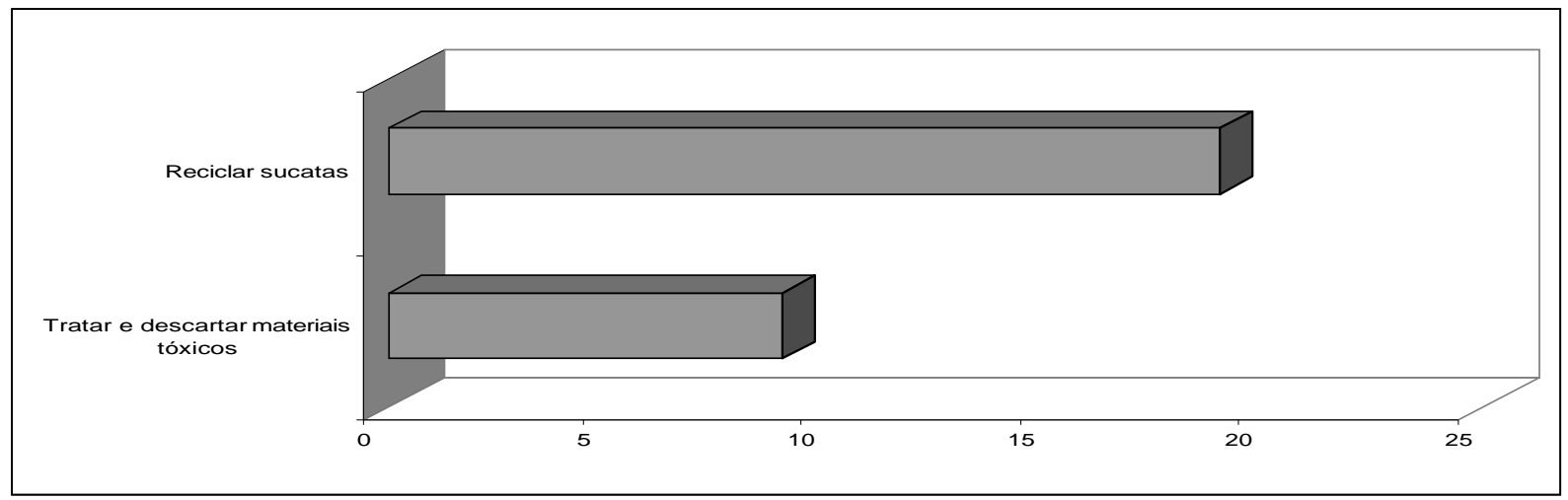

Figura 6. Atividades de falhas ambientais internas Fonte: dados da pesquisa.

Nota-se que 19 empresas executam a reciclagem de sucatas e que 9 tratam e descartam materiais tóxicos. As atividades de operar equipamentos de controle da poluição, manter equipamento de poluição e licenciar instalações para produzir contaminantes não são executadas nos respondentes.

A Figura 7 apresenta os resultados relacionados aos custos de falhas ambientais externas.

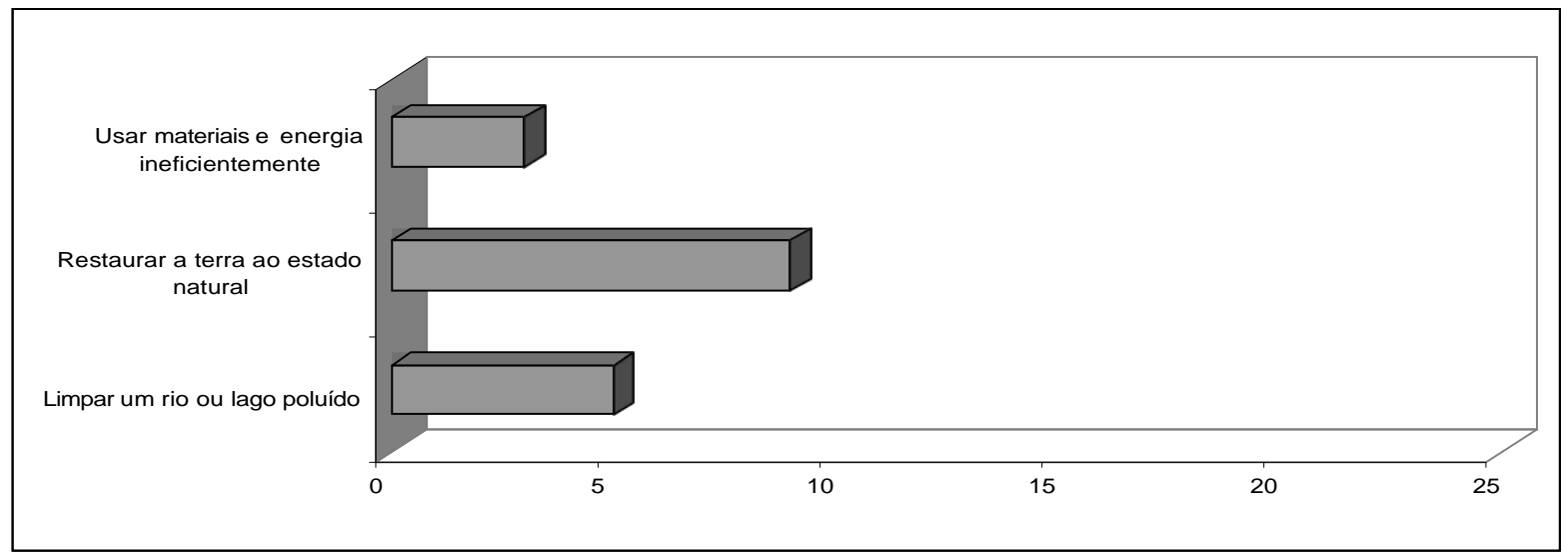

Figura 7. Atividades de falhas ambientais externas Fonte: dados da pesquisa.

Entre as 8 atividades de falhas ambientais externas questionadas apenas 3 são 
realizadas nos respondentes, restaurar a terra ao estado natural, limpar um rio ou lago poluído e usar materiais e energia ineficientemente. Entre os itens não executados nas madeireiras estão: indenizar danos materiais (relacionados ao meio ambiente); perder vendas devido a má reputação ambiental; dar cuidados médicos devido a ar poluído; perder um rio ou lago de uso recreativo (degradação); e, danificar ecossistemas devido ao descarte de resíduos sólidos (degradação).

Diante do exposto, pode-se observar que as indústrias madeireiras analisadas priorizam os custos de detecção e prevenção ambiental e minimizam a ocorrência das falhas relacionadas ao processo produtivo e ao meio ambiente. Tal atitude das empresas encontra suporte na teoria. Conforme (Graedel e Allenby, 1996) e (Hansen e Mowen, 2001), a abordagem pró- ativa, baseada na prevenção de danos ambientais, pode ser menos oneroso que os custos ambientais de falhas internas e externas.

Ressalta-se que a pesquisa limitou-se somente a coleta de dados qualitativos para identificação das ações executadas pelas empresas referentes às classificações dos custos ambientais, não adentrando nos valores empregados na execução das atividades de prevenção, detecção e de falhas internas e externas. A estratégia de pesquisa utilizada deve- se ao fato de muitos destes custos serem intangíveis, portanto de difícil mensuração.

\section{CONSIDERAÇÕES FINAIS}

O artigo objetivou verificar a gestão ambiental, através da percepção e adoção dos princípios dos indicadores ambientais, e identificar ações associadas aos custos ambientais executadas em indústrias madeireiras. Para tanto, fez-se um estudo exploratório, realizado por meio de um estudo multicasos em indústrias estabelecidas na cidade de Caçador/SC.

O resultado da pesquisa sobre a gestão ambiental foi evidenciado em duas figuras. Na primeira figura demonstrou-se a percepção dos indicadores ambientais, e na segunda figura evidenciou-se a adoção dos princípios dos indicadores ambientais.

Observou-se que de maneira geral as indústrias madeireiras conhecem ou já 
Gestão ambiental e ações associadas aos custos ambientais em indústrias madeireiras de

Caçador, SC

Franciane L. Salamoni, Alessandra V. Gallon, Denise D.N. Machado

ouviram falar sobre os diversos indicadores ambientais. Entretanto, mesmo que a maioria das empresas acredite que a disseminação das informações sobre os indicadores ambientais favorece o setor, em apenas 6 das 23 empresas o responsável pelo manejo tem conhecimento dos IA.

Verificou-se que mesmo que a maioria das indústrias madeireiras do município de Caçador se preocupe em desempenhar uma boa gestão ambiental, já que apresentam relativa adoção dos princípios dos indicadores ambientais, estas ainda têm um longo caminho a trilhar na busca pela harmonia com o meio ambiente.

Com relação a identificação dos custos ambientais, constatou-se que as ações executadas pelas indústrias madeireiras são essencialmente de custos de detecção e prevenção ambiental. Sua ação pró-ativa à gestão de custos ambientais é promitente em termos de prevenção de danos ambientais e, consequentemente, em redução de custos. Sendo assim, a atitude das empresas encontra suporte na teoria que afirma que a abordagem pró-ativa, baseada na prevenção de danos ambientais pode ser menos oneroso que os custos ambientais de falhas internas e externas.

\section{REERÊNCIAS}

ANDRADE, R.; TACHI ZAWA, T. e CARVALHO, A. B. 2002. Gestão ambiental: enfoque estratégico aplicado ao desenvolvimento sustentável. São Paulo, Makron Books, 246 p. BARBIERI, J.C. 2004. Gestão ambiental empresarial. São Paulo, Saraiva, $344 \mathrm{p}$.

BAZZANELLA, A. 2004. A força econômica de Capital industrial do meio oeste. Revista Caçador, jan: 25-32. CAMMARANO, D.E.I. 2004. Costos Ambientales. In: Congresso Del Instituto Internacional de Custos, 13.

CAMPOS, L.M.S. 1996. Um estudo para definição e identificação dos custos da qualidade ambiental. Florianópolis, SC. Dissertação de mestrado. Curso de PósGraduação em Engenharia da Produção, Universidade Federal de Santa Catarina, $154 \mathrm{p}$.

CERVO, A.L. e BERVI AN, A. 1996. Metodologia científica: para uso dos estudantes universitários. $4^{a}$ ed. São Paulo, McGraw- Hill do Brasil, 144 p.

COLAUTO, R.D. e BEUREN, I.M. 2004. Coleta, análise e interpretação dos dados. I 
n: I.M. BEUREN (org.), Com o Elaborar Trabalhos Monográficos em Contabilidade: teoria e prática. $2^{\underline{a}}$ ed. São Paulo, Atlas, 200 p.

DI AZ- MORENO, A.B. 1999. Possibilidades metodológicas de aplicacion de indicadores ambientales a nível municipal. Revista de Estudos Ambientais, 1(1): 77- 95.

DUARTE, M.D. 1997. Caracterização da rotulagem ambiental de produtos. Florianópolis, SC. Dissertação de mestrado. Curso de Pós-Graduação em Engenharia da Produção, Universidade Federal de Santa Catarina, 120 p.

FERNANDES, K.M. e RODRI GUES, L.C. 2003. Proposta de arquitetura de um sistema de informação externa, para apoio à competitividade da indústria madeireira exportadora de Caçador. Revista de Negócios, 8 (3): 153- 162.

FERREI RA, A.C. S. 2003. Contabilidade Ambiental: uma informação para o desenvolvimento sustentável. São Paulo, Atlas, 144 p.

FEDERAÇÃO das Indústrias do Estado de Santa Catarina (FIESC). 2004. Unidade de Acompanhamento Econômico Industrial. Santa Catarina em dados. Florianópolis, v. 14.

FEDERAÇÃO das Indústrias do Estado de Santa Catarina (FIESC). 2006. Unidade de Política Econômica e Industrial. Diretoria de Relações Industriais. Florianópolis.

FEDERAÇÃO e Centro das indústrias do Estado de São Paulo (FIESP). 2004. Cartilha de indicadores de desempenho ambiental na indústria. São Paulo, FIESP/ Cl ESP, jun., 29 p. Disponível em: http://www.fiesp.com.br/ download/publicacoes_meio_ambiente/cartilha_indic_ambiental.pdf, acesso em $08 / 3 / 2006$.

GOBBI, B.C. e BRI TO, M.J. 2005. Gestão ambiental como prática social em um a organização produtora de celulose: um a análise interpretativa. In: ENANPAD, 29. Curitiba, 2005. Anais... Rio de Janeiro, ANPAD, CD- ROM.

GONÇALVES, S. S. e HELI ODORO, P.A. A 2005. Contabilidade ambiental com o um novo paradigma. Revista Universo Contábil, 1(3): 84-96.

GRAEDEL, T.E. e ALLENBY, B.R. 1996. Design for environment. Upper Saddle River, Prentice Hall, 412 p. HANSEN, D.R. e MOWEN, M.M. 2001. Gestão de custos. São Paulo, Pioneira Thomson Learning, $783 \mathrm{p}$.

MACHADO, D.D.P.N. e GI OMBELLI, V. 2001. Educação Ambiental dos Empregados e a Certificação ISO 14000: um estudo de caso na companhia têxtil alfa. FURB, VI ENGEMA, $154 \mathrm{p}$. 
POSSAMAI, T. 2002. Condicionantes na aplicabilidade de indicadores sociais e ambientais de sustentabilidade. Blumenau, SC. Dissertação de mestrado. Curso de Pós-Graduação em Engenharia Ambiental, Universidade Regional de Blumenau, $151 \mathrm{p}$.

RIBEIRO, M. S. 1992. Contabilidade e meio ambiente. São Paulo, SP. Dissertação de mestrado. Curso de Pós-Graduação em Contabilidade, Universidade de São Paulo, 141 p.

RIBEIRO, M.S. e ROCHA, W. 1999. Gestão estratégica dos custos ambientais. I n: Congresso Brasileiro de Custos, São Paulo, 1999. Anais... São Paulo, ABC/ FEAUSP, CD- ROM.

RI CHARDSON, R.J. 1999. Pesquisa social: métodos e técnicas. 3ª ed. São Paulo, Atlas, $344 \mathrm{p}$.

ROBLES JÚNIOR, A. 2003. Custos da qualidade: aspectos econômicos da gestão da qualidade e da gestão ambiental. $2^{\underline{a}}$ ed. São Paulo, Atlas, 162 p.

ROSEN, C.M. 2001. Environmental strategy and competitive advantage: na introduction. California Management Review, 43.

SINDICATO da Indústria Madeireira de Caçador (SIMCA). 2005. Informativo anual.

SOUZA, R.S. 2002. Evolução e condicionantes da gestão ambiental nas empresas. REAd - Revista Eletrônica de Administração, 8 (6): 85- 112. [ed. especial 30]

THOMÉ, N. 1995. História da devastação da Floresta da Araucária e do desenvolvimento da indústria da madeira em Caçador e na Região do Contestado no século XX. Revista Ciclo da Madeireira, 210 p.

TINOCO, J. E.P. e KRAEMER, M. E.P. 2004. Contabilidade e gestão ambiental. São Paulo, Atlas, $304 \mathrm{p}$.

TRIVIÑOS, A.N. S. 1987. Introdução à pesquisa em ciências sociais: a pesquisa qualitativa em educação. São Paulo, Atlas, 176 p.

WERNKE, R. 2001. Custos ambientais: um a abordagem teórica com ênfase na obtenção de vantagem competitiva. Revista de Contabilidade do CRC- SP, 5(15): 4049.

Data de Submissão: 09/01/2007

Data de Aceite: 01/03/2007 